\title{
$A \beta$ alters the connectivity of olfactory neurons in the absence of amyloid plaques in vivo
}

\author{
Luxiang Cao¹, Benjamin R. Schrank1, Steve Rodriguez', Eric G. Benz¹, Thomas W. Moulia1, \\ Gregory T. Rickenbacher ${ }^{1}$, Alexis C. Gomez ${ }^{1}$, Yona Levites², Sarah R. Edwards', Todd E. Golde², \\ Bradley T. Hyman', Gilad Barnea ${ }^{3} \&$ Mark W. Albers ${ }^{1}$
}

The amyloid beta peptide aggregates into amyloid plaques at presymptomatic stages of Alzheimer's disease, but the temporal relationship between plaque formation and neuronal dysfunction is poorly understood. Here we demonstrate that the connectivity of the peripheral olfactory neural circuit is perturbed in mice overexpressing human APPsw (Swedish mutation) before the onset of plaques. Expression of human APPsw exclusively in olfactory sensory neurons also perturbs connectivity with associated reductions in odour-evoked gene expression and olfactory acuity. By contrast, olfactory sensory neuron axons project correctly in mice overexpressing wild-type human amyloid precursor protein throughout the brain and in mice overexpressing M671V human APP, a missense mutation that reduces amyloid beta production, exclusively in olfactory sensory neurons. Furthermore, expression of $A \beta 40$ or A 342 solely in the olfactory epithelium disrupts the olfactory sensory neuron axon targeting. Our data indicate that altering the structural connectivity and function of highly plastic neural circuits is one of the pleiotropic actions of soluble human amyloid beta.

\footnotetext{
1 Department of Neurology, MassGeneral Institute of Neurodegenerative Disease, Harvard Medical School, Boston, Massachusetts 02129, USA.

2 Department of Neuroscience, University of Florida, Gainesville, Florida 32610, USA. ${ }^{3}$ Department of Neuroscience, Brown University, Providence, Rhode Island 02912, USA. Correspondence and requests for materials should be addressed to M.W.A. (email: albers.mark@mgh.harvard.edu).
} 
$\mathrm{T}$ he pathobiology of Alzheimer's disease (AD) erodes neural networks and their underlying neural circuits, resulting in cognitive deficits and, ultimately, dementia ${ }^{1}$. Accumulations of amyloid beta $(\mathrm{A} \beta)$ peptide assemblies in the cortex, especially amyloid plaques, are present years before the onset of clinical symptoms of $\mathrm{AD}^{2}$. In fact, approximately $30 \%$ of cognitively intact septuagenarians harbour cerebral amyloid plaques ${ }^{3,4}$. Defining the temporal relationship between neural network dysfunction and amyloid deposition is crucial in developing effective therapies for the preclinical stage of $\mathrm{AD}^{5}$.

Transgenic mice overexpressing pathogenic mutated alleles of the human amyloid precursor protein (hAPP) model the cerebral amyloidosis of preclinical $\mathrm{AD}^{6}$. In these models, neurons surrounding amyloid plaques exhibit reduced dendritic spine density and elevated resting intracellular calcium concentrations ${ }^{7,8}$. However, loss of synaptic proteins precede amyloid deposition in these models ${ }^{9}$ and soluble $A \beta$ species disrupt neural network function, for example, inhibiting long-term potentiation, inducing long-term depression and diminishing the density of dendritic spines ${ }^{10,11}$. Lentiviral expression of hAPP, but not M671V hAPP (hAPPmv; M671V, a synthetic missense mutation of $h A P P$, which impairs $A \beta$ generation ${ }^{12}$ ), in hippocampal slice preparations evoked a long-term depressionlike phenotype and reduced spine density in adjacent neurons not expressing hAPP ${ }^{13-15}$. Together, these data indicate that soluble $A \beta$ species, either released from cells or diffusing from the periphery of amyloid deposits, mediate neural circuit dysfunction.

In this study, we probe the actions of human $A \beta$ in the mouse peripheral olfactory neural circuit in vivo, a genetically tractable established model of neuronal connectivity. Interestingly, the neural network underpinning olfactory perception and odour naming is compromised early in $\mathrm{AD}^{16}$. Each mouse olfactory sensory neuron (OSN) expresses a single olfactory receptor (OR), choosing from over 1,000 OR genes ${ }^{17}$. Each OR gene can be modified to express marker proteins or disease genes in a defined OSN cell type with exquisite specificity. To a first approximation, this circuit is organized as over 1,000 parallel channels defined by OR proteins, which govern the response properties to odours ${ }^{18}$ and the sites of axon projection on the surface of the olfactory bulb ${ }^{19,20}$. Collectively, these OR-dictated projection loci form a stereotyped map. We find that overexpression of the Swedish mutation of hAPP (hAPPsw), which causes early onset $\mathrm{AD}^{21}$, disrupts the connectivity of OSNs, reduces activity-dependent gene expression in second-order olfactory neurons and compromises olfactory acuity. These findings are not present in control mouse lines that overexpress wild-type hAPP or hAPPmv. Moreover, expression of $A \beta 40$ or $A \beta 42$ restricted to the olfactory epithelium also disturbs OSN axon targeting. These results indicate that human $A \beta$ induces axon dysfunction in vivo in the absence of amyloid plaques.

\section{Results}

OSN axons mistarget in mice overexpressing hAPPsw. Axons of OSNs expressing the same OR innervate discrete glomeruli on the surface of the olfactory bulb (Fig. 1a). The naturally occurring hAPPsw (K670N, M671L) augments cleavage by the $\beta$-secretase, thereby increasing $A \beta$ production (Fig. $1 \mathrm{~b})^{22}$. We bred Tg2576 mice $^{22}$, which overexpress hAPPsw throughout the brain, including OSNs in the olfactory epithelium (Supplementary Fig. S1), with a mouse line in which the $P 2$ OR gene was modified to also express green fluorescent protein $(\mathrm{GFP})^{20}$. In control animals, a single glomerulus predominantly received fluorescent fibres in each bulb hemisphere. (Fig. 1c,d). By contrast, in littermate animals overexpressing hAPPsw, P2 axon projections terminate within multiple glomeruli per half bulb (Fig. 1e,f).

To confirm this phenotype, we examined a distinct subpopulation of OSNs expressing a different OR, MOR28. In control mice, axons labelled with an antibody against MOR $28^{23}$ projected to only one glomerulus per half bulb (Fig. 1g,h). However, in Tg2576 mice, multiple adjacent glomeruli per half olfactory bulb received MOR28labelled fibres (Fig. 1i,j). This phenotype was observed in both males and females, and at ages ranging from 10 days to 12 months. Thus, mistargeting of axons in the olfactory system occurs before plaque deposition in the olfactory bulbs of Tg2576 mice (Fig. 1k-n).

Intact targeting in mice overexpressing wild-type hAPP. In I5 mice overexpressing the wild-type hAPP gene $(h A P P w t)^{9}$, immunostaining of the olfactory epithelium revealed robust expression of $h A P P w t$ in OSNs (Fig. 2a,b). We bred the I5 mouse line with a line in which the P2 OR gene was modified to also express the fusion protein mouse tau- $\beta$-galactoside $\left(\right.$ tau-LacZ) ${ }^{20}$. Immunostaining of the olfactory bulb using an anti-LacZ antibody did not reveal differences in targeting of axons of OSNs expressing P2 (Fig. 2c,d). Similiarly, the fidelity of targeting of axons of OSNs expressing MOR28 was also preserved (Fig. 2e,f) relative to littermate controls. These preserved axon projection patterns suggest that overexpression of the hAPPsw allele alters connectivity of this neural circuit.

Selective expression of hAPPsw in OSNs alters connectivity. To determine whether expression of hAPPsw exclusively in OSNs was sufficient to cause OSN axon mistargeting, we generated transgenic mouse lines that coexpress hAPPsw and the axonal marker human placental alkaline phosphatase (PLAP) in a conditional manner using the tetracycline transcriptional activator (TTA)/TetO system ${ }^{24}$. These transgenic lines were crossed with a mouse line wherein the olfactory marker protein $(O M P)$ gene was modified to co-express TTA (Fig. 3a ${ }^{25}$. Immunohistochemical analysis of the olfactory epithelium of compound heterozygote mice demonstrated that a subset of the OSNs express hAPPsw (Fig. 3b,c). Immunostaining of the olfactory bulb indicated that OSNs expressing PLAP project broadly to the glomeruli of the olfactory bulb (Fig. 3d,e). Overall, approximately $12 \%(319 / 2653)$ of OSNs expressed the transgene products hAPPsw and PLAP, except in the very lateral region where the expression was markedly reduced, $1.4 \%$ (28/2017). The proportion of expression in the M71-defined subpopulation was $18.4 \%$ (28 hAPP + /152 OSNs), but the expression of hAPPsw in the lateral OSNs-expressing MOR28 was $0.19 \%$ (5 hAPP + /2604 OSNs). Importantly, we do not observe a shift in the pattern of expression of ORs over the olfactory epithelium. This mouse line expressing hAPPsw and PLAP was termed CORMAP (Conditional, Olfactory Sensory Neuron-Restricted Mosaic expression of $\underline{\text { APPsw }}$ and PLAP).

Immunostaining of CORMAP mice bearing a modified P2 gene, also expressing the tau-LacZ fusion protein ${ }^{20}$, revealed multiple glomeruli receiving fibres labelled with LacZ, which was significantly different from immunostaining littermate P2/tau-LacZ mice expressing only the TTA transcription factor alone (Fig. $3 \mathrm{f}-\mathrm{h}$; $P<0.001$; two-tailed Student's $t$-test; $n=15$ (control); $n=18$ (CORMAP)). Similarly, crossing CORMAP mice with a mouse line with a modified M71 gene, also expressing the tau-LacZ fusion protein ${ }^{26}$, revealed multiple glomeruli receiving LacZ fibres per half bulb (Fig. 3i-k; $P<0.04$; two-tailed Student's $t$-test; $n=17$ (control); $n=12$ (CORMAP)). OSNs-expressing MOR28 predominantly targeted one glomerulus per half bulb in CORMAP mice and control littermates (Fig. 31-n); the intact targeting likely reflects the scant transgene expression in that region of the epithelium. Overall, the axon guidance phenotypes were similar to those observed in Tg2576, indicating that restricted expression of hAPPsw to OSNs is sufficient to disrupt their axon targeting.

Selective expression of hAPPmv in OSNs maintains connectivity. As hAPPsw facilitates production of $A \beta$, we generated transgenic mouse lines that coexpresses hAPPmv (Fig. 1b), a hAPP isoform that impairs $A \beta$ production ${ }^{12}$, and the axonal marker mCherry 
a

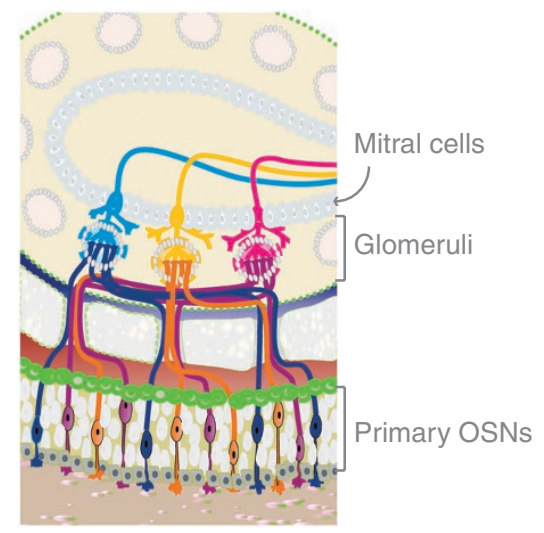

b

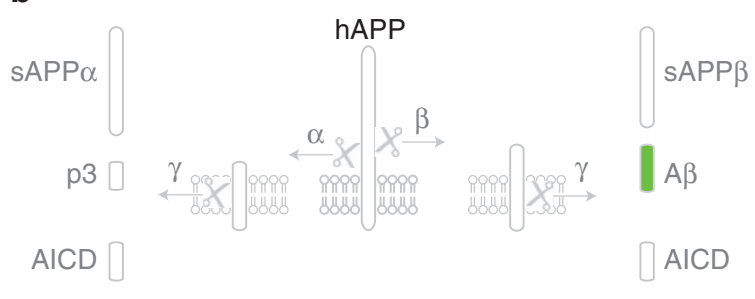

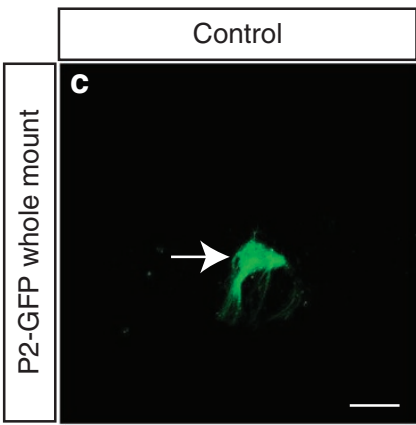

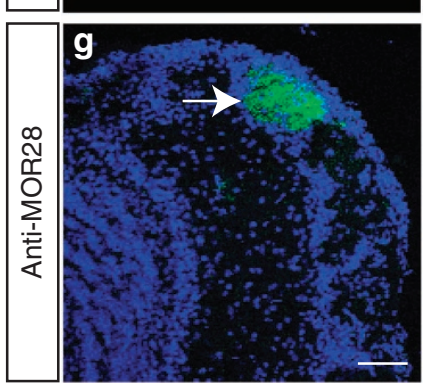

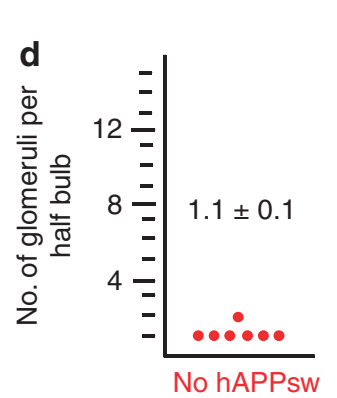

$\mathrm{h}$

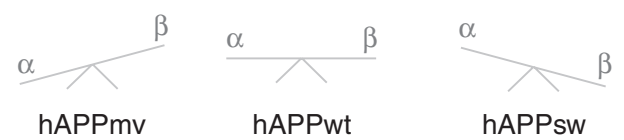

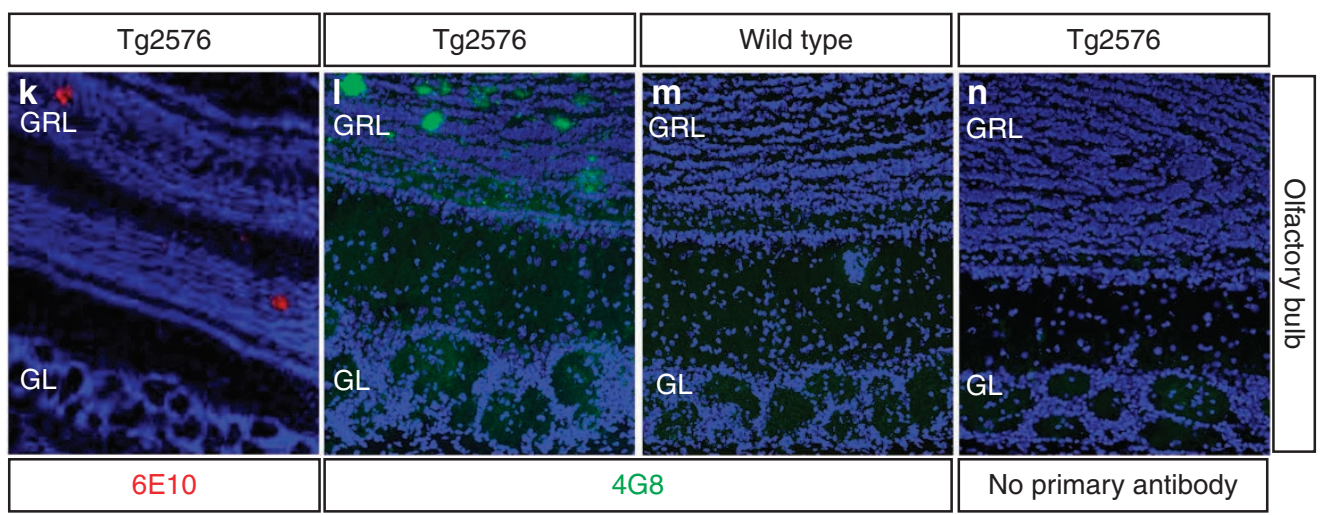

Figure 1 | Aberrant OSN projections in transgenic mouse lines overexpressing hAPPsw. (a) Schematic representation of the anatomy of the peripheral olfactory neural circuit demonstrating that choice of olfactory receptor (OR) (depicted by colour) dictates the projection target of its axon in the olfactory bulb. (b) Schematic representation of the protease cleavage pathways to generate A $\beta$ and other fragments from hAPP. The mutation hAPPsw enhances flux through the $\beta$-secretase pathway, and M671V hAPP (hAPPmv) impairs flux through the $\beta$-secretase pathway. (c,d) Representative image of olfactory bulbs from P2-ires-GFP mice reveal a single glomerulus (indicated by arrow) per half bulb is targeted by axons containing GFP (each dot represents result per half bulb). (e,f) Representative image and quantification of olfactory bulbs from Tg2576 (panneuronal hAPPsw)/P2-ires-GFP mice reveal aberrant targeting of fibres containing GFP to multiple glomeruli (arrows) per half bulb ( $P<0.02$, two-tailed Student's $t$-test; $n=7$ (controls); $n=6$ (Tg2576)). $(\mathbf{g}, \mathbf{h})$ Representative coronal section and quantification of olfactory bulbs from wild-type mice immunostained with anti-MOR28 and TOTO-3 reveal targeting to a single glomerulus (arrow). (i,j) Representative coronal section and quantification of olfactory bulbs from Tg2576 hAPPsw mice immunostained with anti-MOR28 and TOTO-3 reveal aberrant targeting of MOR28 axons to multiple glomeruli (arrows; $P<0.05$, two-tailed Student's $t$-test; $n=8$ (controls); $n=11$ (Tg2576)). Data presented as means \pm s.e.m. (k) The olfactory bulb from a 13-month-old Tg2576 mouse immunostained with 6 E10 anti-APP antibody shows the presence of plaques in the granule cell layer (GRL). No plaques are seen in the glomerular layer (GL). (I-n) The humanspecific antibody 4G8 reveals expression of hAPPsw in the glomerular layer (GL) of Tg2576 (24 months old), but not in wild-type mice (m) or when 4G8 is omitted from the Tg2576 tissue (n). Plaques are seen in GRL but not in the GL cell layers in the 24-month-old Tg2576 mouse (I). Scale bar $=100 \mu \mathrm{m}$. 

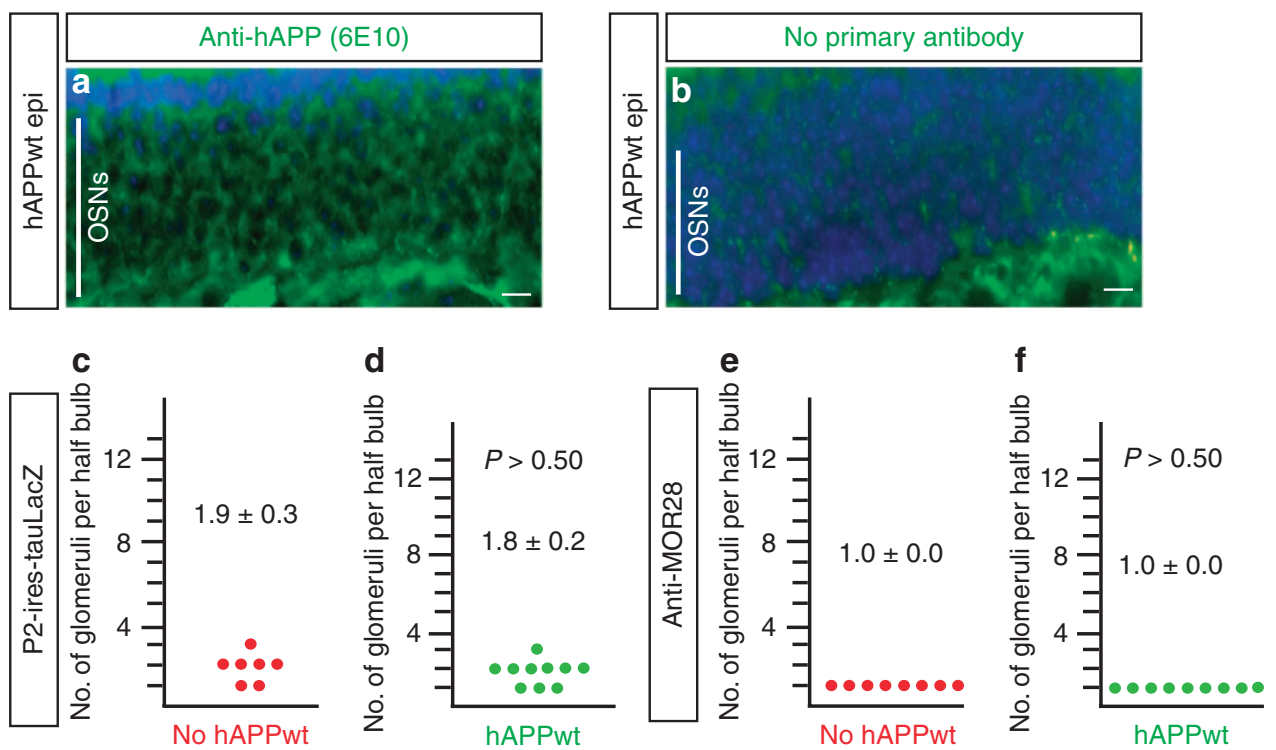

Figure 2 | Preserved OSN projections in transgenic mouse lines overexpressing hAPPwt. (a,b) Olfactory epithelia harvested from 12-week-old mice overexpressing the hAPP protein driven by the platelet-derived growth factor (PDGF) $\beta$-promotor expressed APP as shown by immunostaining with antiAPP 6E10 (a) relative to a no primary antibody control (b). Scale bar $=20 \mu \mathrm{m}$. (c,d) Quantification of olfactory bulbs from control 1-year-old P2-ires-GFP mice and from 15 human wild-type APP (hAPPwt)-overexpressing mice reveal targeting of fibres containing GFP to two glomeruli per half bulb in both lines ( $P>0.50$, two-tailed Student's t-test; $n=7$ (controls); $n=10$ (I5)). (e,f) Quantification of olfactory bulbs from control mice and from I5 hAPPwt transgenic mice immunostained with anti-MOR28 reveal targeting to a single glomerulus $(P>0.50$, two-tailed Student's $t$-test; $n=8$ (controls); $n=9$ (I5)). Scale bar $=100 \mu \mathrm{m}$. Data presented as means \pm s.e.m.

in a conditional manner as described above (Fig. 4a). Similarly, a subset of medial OSNs $(17.6 \% ; 239 / 1366)$ expressed hAPPmv and mCherry (Fig. 4b,c), and smaller subset of lateral OSNs (4.7\%; 37/782) expressed the transgene. OSNs expressing mCherry projected broadly to the glomeruli in the olfactory bulb (Fig. 4d,e). The proportion of transgene expression in the MOR28-defined subpopulation mirrored the ambient density of the lateral epithelium (4.6\%; 26 hAPP + /568 OSNs). Moreover, we did not observe a shift in the pattern of expression of ORs over the olfactory epithelium. This mouse line expressing hAPPmv and mcherry was termed CORMAC (Conditional, Olfactory Sensory Neuron-Restricted Mosaic expression of $\underline{A} P P m v$ and mCherry). The number of glomeruli targeted by OSNs coexpressing P2 and tau-LacZ in CORMAC mice was similar to control littermates (Fig. $4 \mathrm{f}-\mathrm{h}$ ). Similarly, the distribution of targeted glomeruli by M71-expressing OSNs did not differ between CORMAC mice and control littermates (Fig. 4i-k). Moreover, predominantly one glomerulus per half bulb was labelled with an antibody against MOR28 in both hAPPmv and control littermates (Fig. 41-n). In summary, the patterns of connectivity of OSNs in CORMAC mice were preserved, thus demonstrating the specificity of the hAPPsw phenotype.

A mouse line overexpressing a synthetic APP isoform (mouse/ human chimeric protein with Swedish and Indiana mutations) was recently reported to generate high levels of human $A \beta$, which in turn caused accelerated OSN death ${ }^{27}$. In our study, levels of activated caspase- 3 and the density of OSN subpopulations in Tg2576, CORMAP or CORMAC lines were not significantly different from control littermates (Supplementary Fig. S2).

Olfactory deficits correlate with altered connectivity. The OSNspecific restricted expression of hAPP isoforms in both CORMAP and CORMAC lines affords the opportunity to determine the functional consequence of these connectivity deficits using odourevoked behavioural assays without the potential confounds that central neural circuits may be affected by hAPP expression. We assessed olfactory function in these lines using two paradigms. The response to 2,3,5-trimethyl-3-thiazoline (TMT), an odourant isolated from fox faeces with an innate aversive response to mice, was monitored (Fig. 5a $)^{28}$. CORMAP, but not CORMAC, mice spent significantly more time within region of the arena where TMT was present (Fig. 5b,c). Moreover, in an olfactory assay monitoring appetitive behaviour $^{29}$, food-restricted CORMAP mice took significantly more time to find food buried under mouse bedding relative to littermate controls (Fig. 5d,e). Together, these olfactory assays indicate that compromised olfactory function correlates with alterations in structural connectivity of the peripheral olfactory neural circuit.

Reduced expression of activity-dependent gene products. To confirm that the functional responses of OSNs was compromised in the CORMAP line, we quantified tyrosine hydroxylase $(\mathrm{TH})$ expression by periglomerular dopaminergic neurons as a surrogate marker of OSN input activity ${ }^{30}$. Statistically significant reductions in levels of the TH signal were measured in the glomerular layer of CORMAP mice relative to wild-type littermates (Fig. $6 \mathrm{a}-\mathrm{c} ; P<0.01$; two-tailed Student's $t$-test; $n=5$ mice per genotype) that had been housed in the same cage. In addition, we quantified the expression of the immediate early gene $A r c$ in periglomerular and tufted neurons of CORMAP mice relative to littermate controls. We observe a significant reduction in the number of neurons expressing Arc (Fig. 6d-f; $P<0.01$; two-tailed Student's $t$-test; $n=60-100$ per genotype). As periglomerular and tufted neurons in the olfactory bulbs of CORMAP mice do not express hAPPsw, we interpret these reduced levels of TH and Arc as reflecting reduced input from OSNs.

Expression $\mathrm{A} \beta 40$ or $\mathrm{A} \beta 42$ disturbs OSN axon targeting. The specificity of the hAPPsw phenotype implies that a beta-site APP cleaving enzyme 1 (BACE1) cleavage product of APP mediates axon dysfunction of OSNs. To determine whether the expression of human $\mathrm{A} \beta$ disrupts axon targeting of OSNs, we transduced the olfactory epithelia of mice with adeno-associated virus (AAV) 

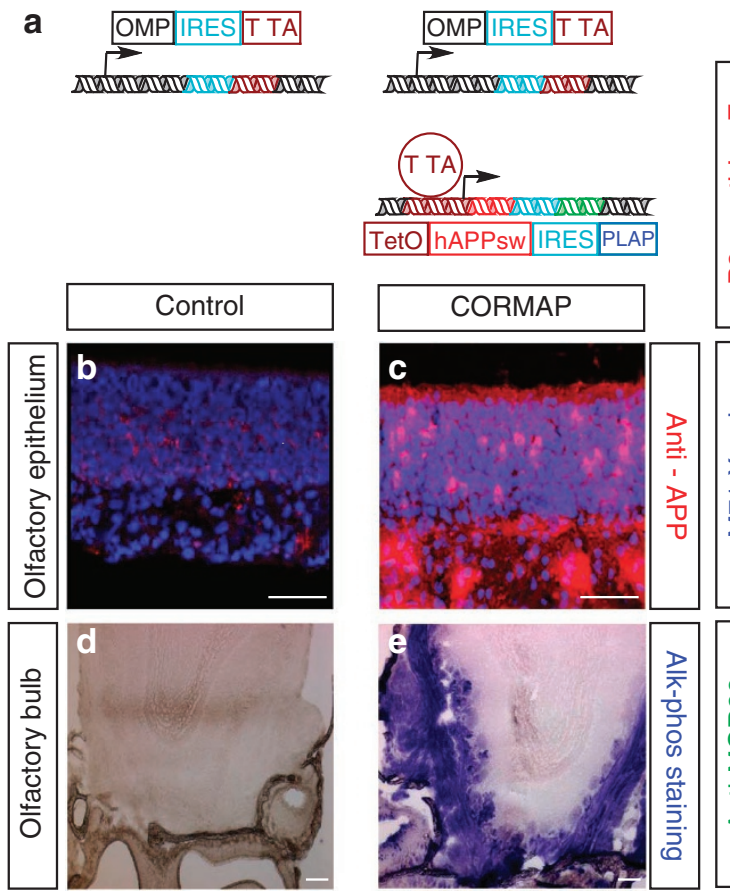
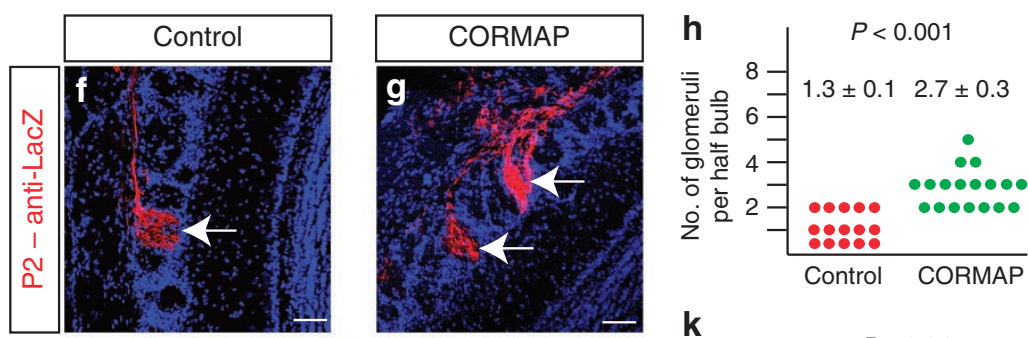

$\mathbf{k}$
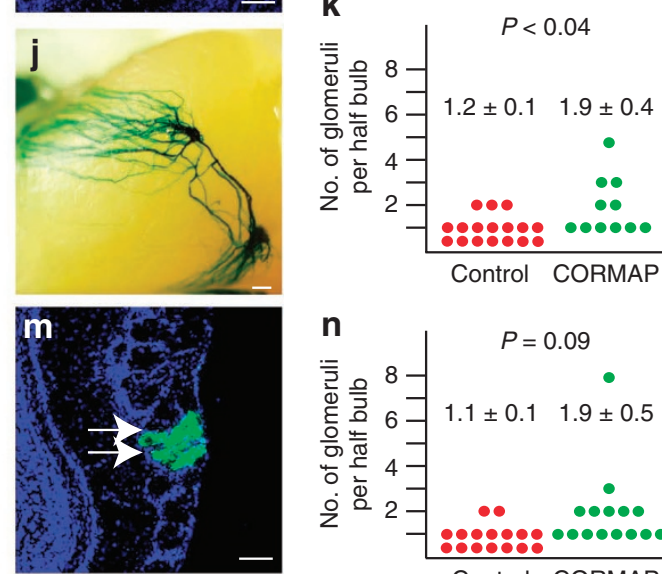

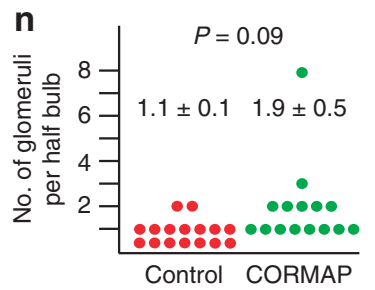

Figure 3 | Characterization of CORMAP mice. (a) Schematic diagram of the olfactory marker protein (OMP) gene locus altered by homologous recombination to introduce the internal ribosomal entry sequence (IRES) and tetracycline transcriptional activator (TTA; OMP-ivt) and the transgene encoding the operator sequence TetO followed by hAPPsw, IRES and PLAP. (b,c) Coronal section of the medial olfactory epithelium from a control and a CORMAP mouse immunostained with an anti-APP antibody reveals background expression of the endogenous mouse APP in OSNs and $12 \%$ of OSNs

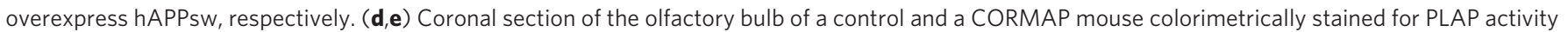
reveals that PLAP-labelled fibres target glomeruli in a stochastic pattern. (f-h) Representative images and quantification of olfactory bulbs from P2-irestauLacZ (tau- $\beta$-galactosidase fusion protein)/OMP-ivt and P2-ires-tauLacZ/CORMAP mice reveal targeting of LacZ-bearing neurons to one glomerulus (arrow) in control mice and targeting of LacZ-bearing axons to multiple glomeruli (arrows) in CORMAP mice (arrows identify glomeruli revealing P2expressing fibres; $P<0.001$, two-tailed Student's $t$-test; $n=15$ (controls); $n=18$ (CORMAP)). (i-k) Representative images and quantification of olfactory bulbs from M71-ires-tauLacZ/OMP-ivt and littermate M71-ires-tauLacZ/CORMAP mice reveal targeting of LacZ-bearing neurons to one glomerulus in controls and to multiple glomeruli in CORMAP mice, with some fibres crossing between the lateral and medial projection loci. ( $P<0.04$, two-tailed Student's t-test; $n=17$ (controls); $n=11$ (CORMAP)). (I-n) Representative images and quantification of olfactory bulbs from control and littermate CORMAP mice stained with anti-MOR28 antibody reveals MOR28-bearing axons targeting predominantly to a single glomerulus per half bulb in both lines ( $P<0.09$, two-tailed Student's $t$-test; $n=16$ (controls); $n=15$ (CORMAP)). Scale bars $=100 \mu \mathrm{m}$, except for $(\mathbf{d}, \mathbf{e})$ and $(\mathbf{i}, \mathbf{j})$ where scale bar $=200 \mu \mathrm{m}$. Data presented as means \pm s.e.m.

expressing either the Bri-A $\beta 40$ fusion protein or the Bri-A $\beta 42$ fusion protein, which are cleaved sequentially by furin to secrete the human $A \beta 40$ or $A \beta 42$ peptide, respectively ${ }^{31}$. We instilled one naris of M71/tau-LacZ mice with AAV8 expressing either Bri$A \beta 40$ or Bri-A $\beta 42$. The uninfected side served as a control. After 12 weeks, examination of M71-expressing OSNs revealed disturbed axon targeting on the infected side compared with the noninfected side (Fig. 7a-c). In control experiments, infection of AAV8 expressing GFP in one naris did not disturb M71 axon targeting (data not shown). Immunostaining of the olfactory epithelia from infected mice using the anti-hAPP and A $\beta$ antibody $6 \mathrm{E} 10$ revealed expression in the superficial layers of the olfactory epithelium. The cells expressing human $\mathrm{A} \beta 40$ co-stained with a marker for nonneuronal sustentacular cells (Supplementary Fig. S3a-d). Similarly, the infected side with Bri-A $\beta 42$-expressing virus also caused axon mistargeting of M71-expressing axons (Fig. 7d-f). Of note, immunostaining of both the infected olfactory epithelium and the ipsilateral olfactory bulb with $6 \mathrm{E} 10$ did not reveal evidence of amyloid deposition (Supplementary Fig. S3e); moreover, formic acid extraction of the olfactory bulbs from the Bri-A $\beta 42$-infected mice followed by enzyme-linked immunosorbent assay did not detect $\mathrm{A} \beta 42$ (data not shown). These data support an extracellular mechanism of action of $A \beta$ (that is likely to be soluble) to disturb axon targeting of OSNs. We cannot exclude the possibility that other cleavage products of APP contribute to the hAPPsw phenotype.

\section{Discussion}

The increasing awareness of the susceptibility of olfactory acuity in people with prodromal neurodegenerative disease, relative to other sensory modalities, and our deeper understanding of the physiology underlying olfactory perception ${ }^{32,33}$ have made the olfactory neural network in animals a more widely used model to investigate mechanisms of neurodegenerative disease ${ }^{34,35}$. The amenability of the mouse peripheral olfactory neural circuit to genetic, imaging and behavioural characterization renders it a powerful model system to elucidate the actions of disease proteins ${ }^{16,27}$. One of the unique aspects of this neural circuit is the continuous renewal of OSNs in adults ${ }^{36}$, necessitating precise axon targeting throughout its lifetime to maintain the integrity of the circuit. We exploit this physiologic structural plasticity to visualize dysfunction caused by the expression of genes that cause neurological disease. Here, we report that expression of the Swedish mutation of hAPP in mice in vivo alters the connectivity and function of the peripheral olfactory neural circuit in the absence of plaques. 
a
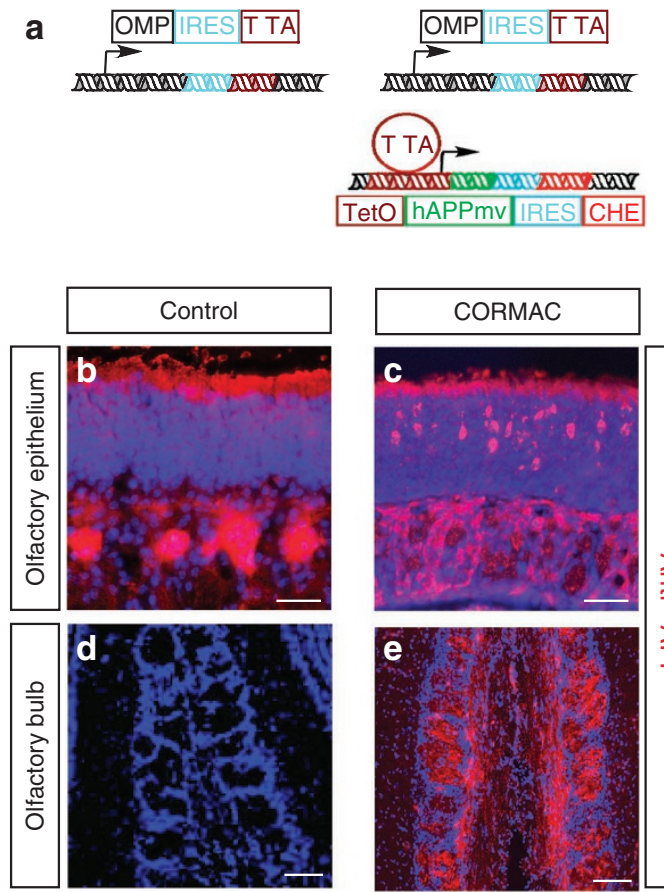
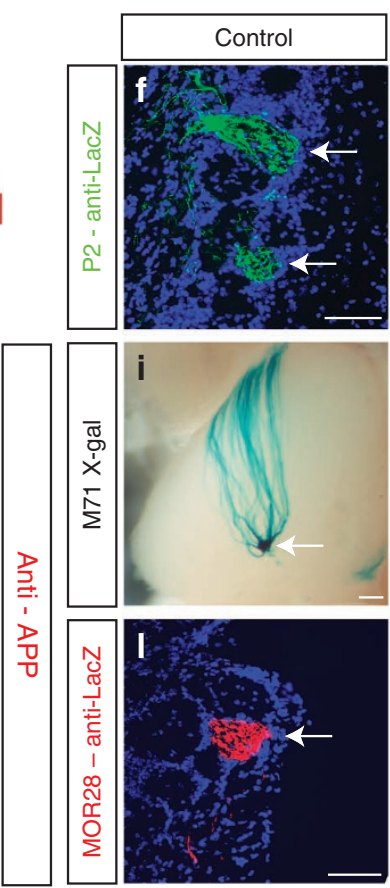
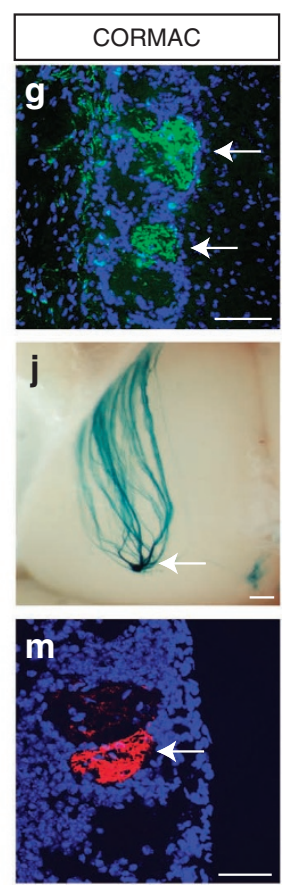

h

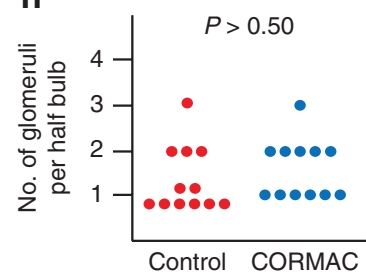

$\mathbf{k}$
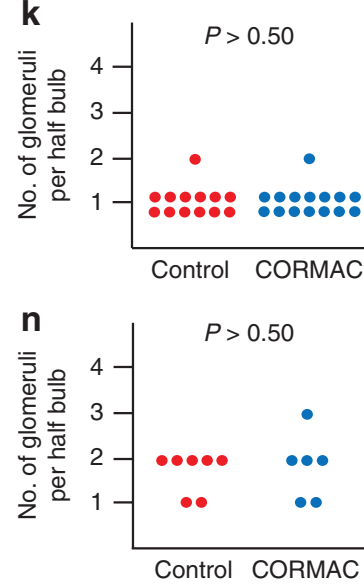

Figure 4 | Characterization of CORMAC mice. (a) Schematic diagram of the OMP gene locus altered by homologous recombination to introduce the IRES and TTA(OMP-ivt) and the transgene encoding the operator sequence TetO followed by hAPPmv (hAPP M671V), IRES and the mCherry (CHE). $(\mathbf{b}, \mathbf{c})$ Coronal section of the medial olfactory epithelium from control and CORMAC mice immunostained with an anti-APP antibody reveals background expression of the endogenous mouse APP in OSNs and $18 \%$ of OSNs overexpressing hAPPmv, respectively. (d,e) Coronal sections of olfactory bulbs from a control mouse and a CORMAC mouse reveal fibres containing mCherry target glomeruli in a stochastic pattern. (f-h) Representative images and quantification of olfactory bulbs from P2-ires-tauLacZ/OMP-ivt and P2-ires-tauLacZ/CORMAC mice reveal targeting of LacZ-bearing neurons to equal glomeruli (arrows) in both control and CORMAC mice. ( $P>0.50$, two-tailed Student's $t$-test; $n=12$ (controls); $n=12(C O R M A C)$ ). (i-k) Representative images and quantification of olfactory bulbs from M71-ires-tauLacZ/OMP-ivt and littermate M71-ires-tauLacZ/CORMAC mice reveal targeting of LacZ-bearing neurons to one glomerulus in both control and CORMAC mice. ( $P>0.50$, two-tailed Student's $t$-test; $n=13$ (controls); $n=15$ (CORMAC)). (I-n) Representative images and quantification of olfactory bulbs from MOR28-ires-tauLacZ/OMP-ivt and littermate MOR28-ires-tauLacZ/CORMAC mice reveal targeting of LacZ-bearing neurons to one glomerulus (arrow) in both control and CORMAC mice $(P>0.50$, two-tailed Student's $t$-test; $n=7$ (controls); $n=6($ CORMAC)). Scale bars $=100 \mu \mathrm{m}$, except for $(\mathbf{i}, \mathbf{j})$ where scale bar $=200 \mu \mathrm{m}$.

Our initial observation of this axon guidance phenotype occurred in well-characterized lines that overexpress hAPPsw throughout the brain. Taking advantage of methodology to specifically express genes in the peripheral olfactory neural circuit ${ }^{37}$, we generated and examined two lines of mice that overexpress hAPP alleles exclusively in the presynaptic neurons of this circuit. $A \beta$ production is facilitated in one line that expresses hAPPsw and impeded in the other line that expresses hAPPmv ${ }^{12}$. Overproduction of hAPPsw in the presynaptic neurons was sufficient to perturb the structural connectivity of the peripheral olfactory neural circuit. The absence of a phenotype in the hAPPmv line corroborated our findings in the mouse line overexpressing the wild-type form of hAPP. Together with preserved fidelity of axon targeting in the I5 line overexpressing wild-type hAPP throughout the brain, these important controls indicate that overexpression of hAPP is not sufficient to alter OSN axonal connectivity. Rather, our findings suggest that products of BACE1-mediated cleavage of APP critically modulate neuronal function-in congruence with results from studies in hippocampal slices ${ }^{13,15,38}$, in induced human neurons derived from skin fibroblasts ${ }^{39}$ and studies of BACE1 heterozygous and null mice ${ }^{40}$.

We postulate that $A \beta$ is the BACE1 cleavage product of APP involved in mediating the connectivity phenotype. The presence of the connectivity phenotype in mice expressing hAPPsw, but not in the I5 line expressing hAPPwt and the CORMAC line expressing hAPPmv, supports this hypothesis. Moreover, expression of human $A \beta 40$ or human $A \beta 42$ in the olfactory epithelium using a viral vector delivered intranasally phenocopies the alteration in the projection map of OSN axons. As we observe these axon targeting deficits in young mice before the onset of plaques in the broadly expressing lines and as we do not observe amyloid plaques in lines that overexpress hAPP isoforms exclusively in OSNs or in the virally infected mice, this novel axonal phenotype is independent of amyloid plaque deposition. This phenotype is unlikely to be caused by an in utero anomaly, as we can induce it in adult control mice by intranasal expression of $A \beta 40$ or $A \beta 42$. Together, these data are consistent with a model that soluble $A \beta$ triggers axonal dysfunction in the absence of amyloid plaques in vivo, although we cannot disprove that insoluble $\mathrm{A} \beta$ could also cause similar changes.

In addition to altering structural connectivity, expression of hAPPsw exclusively in OSNs has functional consequences as indicated by two lines of evidence. First, relative to control littermates or CORMAC mice, CORMAP mice exhibit significant reductions in olfactory acuity in two distinct behavioural paradigms, one paradigm employing an odour that evokes an aversive response while the other paradigm employs an odour that evokes an appetitive response. We interpret these olfactory-mediated behavioural responses as reflecting the function of the peripheral olfactory neural circuit in CORMAP and CORMAC lines-an interpretation afforded by the restricted expression pattern of hAPPsw and hAPPmv, respectively. Deficits in an odour habituation paradigm have been reported in Tg2576 mice at ages 6-7 months that correlated with amyloid plaque deposition ${ }^{34}$. By contrast, the behavioural 
a

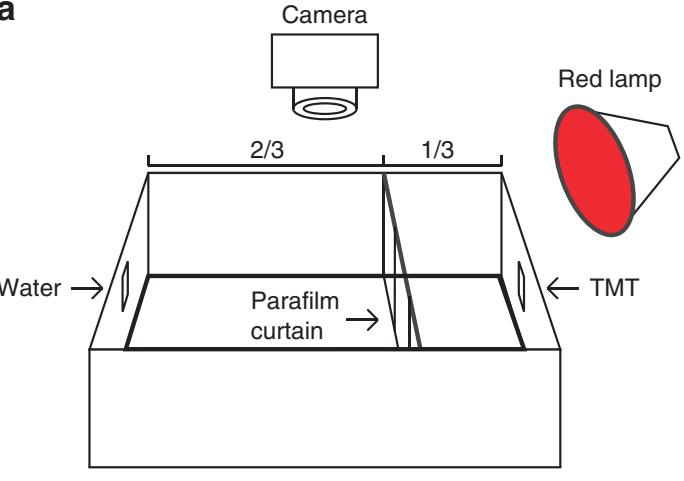

d

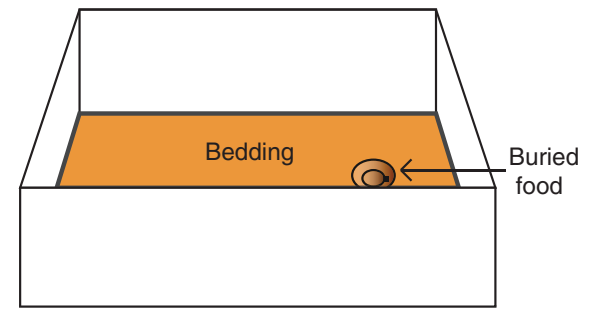

b
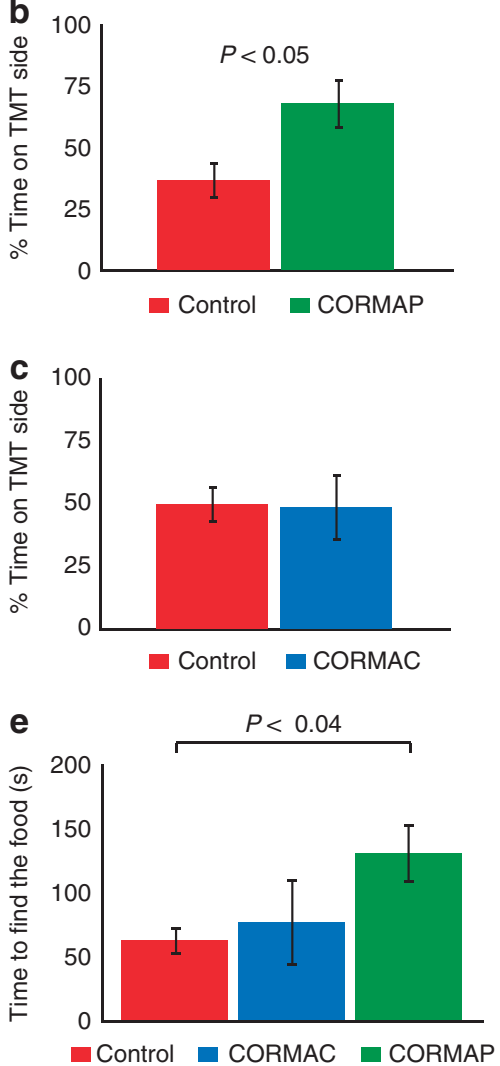

Figure 5 | Olfactory behavioural deficit in the CORMAP mice but not in CORMAC mice. (a) Schematic representation of the behavioural arena to assess the response to 2,3,5-trimethyl-3-thiazoline (TMT), an odour isolated from fox faeces that triggers an innate aversion response in mice. (b,c) Percentage of time that each mouse spent in a compartment with the innately aversive odour TMT relative to a compartment with water for a 3-min period. Relative to littermate controls, CORMAC (hAPPmv) but not CORMAP (hAPPsw) mice avoided TMT. ( $P<0.05$; one-way analysis of variance (ANOVA); $n=5$ pairs of littermate mice for each genotype with ages ranging from 3 to 5 months). (d) Schematic representation of the behavioural arena to find the buried food. (e) Graphical representation of time to find food for controls, CORMAC and CORMAP mice. Relative to controls, CORMAP but not CORMAC required a significantly longer time to find the food $(P<0.04$; one-way ANOVA; $n=4$ (control), three (CORMAC) and four (CORMAP) with ages ranging from 3 to 6 months). Error bars = s.e.m.

phenotype of CORMAP mice is detectable at 3-5 months of age and is independent of amyloid plaques. Second, the expression of two independent activity-dependent markers in postsynaptic neurons in the olfactory bulb were significantly reduced in CORMAP mice relative to littermate controls. The magnitude of reduction of these activity-dependent markers $(\sim 25 \%)$ exceeds the frequency of expression of hAPPsw in mature OSNs ( 12\%). This disproportional response in the functional data raises the possibility that hAPPsw may be acting in a non-cell autonomous manner, as seen in studies in hippocampal slices by Malinow's laboratory ${ }^{13,38}$. Our attempts to determine whether a non-cell autonomous mechanism underlies the structural connectivity phenotype in the CORMAP line have not been conclusive to date. Future studies employing expression of hAPP isoforms by specific OR promotors are aimed to address this question directly.

Our data illustrate a detrimental effect of heightened $A \beta$ levels on a neural circuit in the absence of plaques. The CORMAP line offers a quantifiable outcome of the actions of hAPPsw, and likely A $\beta$, which is distinct from amyloid plaque production and that could be utilized to assess therapies targeting aberrant neural plasticity due to $A \beta$. Although olfactory deficits have been shown in patients with prodromal and mild $\mathrm{AD}$, demonstration of alterations in the map of OSN projections in the human olfactory bulb in $\mathrm{AD}$ is necessary to postulate that the CORMAP mouse is a model for the disease. Increasing evidence indicates that $A \beta$ levels rise after neuronal injury by increased expression of APP and/or BACE1 ${ }^{41}$. Established risk factors for late-onset $\mathrm{AD}$, for example, head trauma and vascular insults, result in elevated $A \beta$ production ${ }^{42}$. Further delineation of the mechanism of action of human $A \beta$ in this model system may provide insight into neural circuit and network dysfunction in the long, preclinical stage of $\mathrm{AD}$.

\section{Methods}

Animals. All experiments were in accordance with protocols approved by the Institutional Animal Care and Use Committee of Massachusetts General Hospital. Tg2576 mice overexpressing hAPPsw ${ }^{22}$ were obtained from Taconic Farms (Hudson, NY, USA). I5 hAPPwt mice ${ }^{9}$ and M71-ires-tauLacZ were obtained from Jackson Labs (Bar Harbor, ME, USA). P2-ires-GFP ${ }^{20}$ and P2-ires-tauLacZ ${ }^{43}$ mice were a gift from Richard Axel.

Generation and characterization of CORMAP and CORMAC mice. Transgenic constructs were generated using the hAPPsw695 cDNA, ires-PLAP ${ }^{44}$ and pBSRV $^{37}$, which contained the tetO sequence followed by an artificial intron and splice site, the Pac site and an SV40 polyadenylation signal. For the CORMAC mice, the hAPPsw695 (K670N; M671L) cDNA was mutated to the mv genotype (M671V) by PCR mutagenesis (Stratagene) and confirmed by sequencing. A DNA fragment encoding ires-mcherry was isolated and the hAPPmv-ires-mcherry fragment was cloned and injected. The founder mouse was crossed with OMP-ires-tTA mice ${ }^{25}$. Compound heterozygote mice of the founders for the CORMAP line expressed hAPPsw and PLAP in $\sim 12 \%$ of OSNs and not elsewhere in the brain. This line was backcrossed into C57/BL6 for six generations. Compound heterozygote mice of a founder for the CORMAC line expressed hAPPsw and mCherry in approximately $18 \%$ of OSNs and not elsewhere in the brain. This line was backcrossed into 

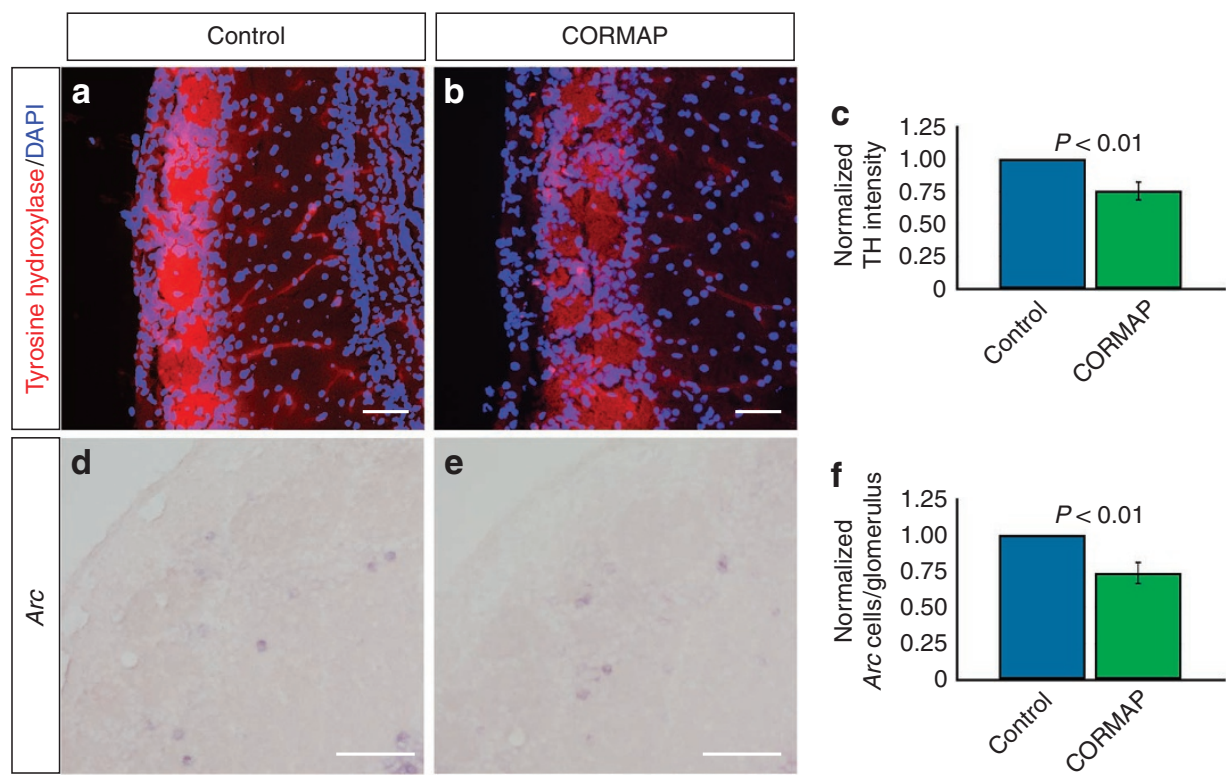

Figure 6 | Reduced induction of OSN activity-dependent genes in CORMAP mice olfactory bulbs. (a) Representative image of olfactory bulbs from a control mouse immunostained with an antibody recognizing tyrosine hydroxylase (TH; red) and a nuclear stain (blue). (b) Representative image of olfactory bulbs from a CORMAP mouse immunostained with an antibody recognizing TH (red) and a nuclear stain (blue). (c) Quantification of the intensity of TH staining in glomeruli of CORMAP ( $n=5$ bulbs) and littermate control mice $(n=5$ bulbs) reveals a statistically significant difference ( $P<0.01$; two-tailed Student's t-test). (d) Representative image of an olfactory bulb from a control mouse following in situ hybridization with an antisense Arc probe. (e) Representative image of an olfactory bulb from a CORMAP mouse following in situ hybridization with an antisense Arc probe. (f) Quantification of number of periglomerular and tufted neurons expressing Arc in matched regions of the olfactory bulbs from CORMAP $(n=5)$ and littermate control mice $(n=5)$ reveals a significant difference $(P<0.01$; two-tailed Student's $t$-test; $n=60-100$ per genotype $)$. Scale bar $=100 \mu \mathrm{m}$. Error bars $=$ s.e. $\mathrm{m}$.

C57/BL6 for six generations. The ages of mice used in this study ranged from 3 weeks to 1 year.

Immunohistochemistry. Standard procedures were used as previously described ${ }^{45}$ The mice were anaesthetized with an intraperitoneal injection of 3,3,3-tribromoethanol (1.25\% in PBS $30 \mu \mathrm{lg}^{-1}$ body weight). Following thoracotomy, intracardiac perfusion with $10 \mathrm{ml}$ of PBS (pH 7.4) was performed. For anti-GFP and anti-LacZ immunostaining, the mice were subsequently perfused with $2 \%$ paraformaldehyde in PBS (pH 7.4). The olfactory turbinates and olfactory bulbs were dissected intact, incubated in $30 \%$ sucrose in PBS at $4{ }^{\circ} \mathrm{C}$ overnight and embedded in optical coherence tomography (Sakura) or M1 (Shandon) in a dry ice/ethanol bath. Twenty micrometre coronal sections were cut on a cryostat (Microm) and collected on SuperFrost slides (Fisher). For immunostaining using the MOR28 and M71 antibodies, the sections were post-fixed with $1 \%$ paraformaldehyde in PBS for $8 \mathrm{~min}$ at room temperature. All sections were washed three times in PBS for $10 \mathrm{~min}$, permeabilized in $0.1 \%$ Triton X-100 in PBS (PT) for $30 \mathrm{~min}$ at room temperature, blocked in 5\% heat-inactivated horse serum in PT (PTS) for $1 \mathrm{~h}$ at room temperature, incubated with primary antibody in PTS under a Hybrislip (Invitrogen) overnight in a humidified chamber at $4{ }^{\circ} \mathrm{C}$, washed three times with PT for $10 \mathrm{~min}$, blocked with PTS for $30 \mathrm{~min}$ at room temperature, incubated with a fluorescent-conjugated secondary antibody in PTS with DAPI (Invitrogen, 1/1000) for $2 \mathrm{~h}$ at room temperature, washed briefly in PBS, and Vectashield was applied to each slide and coverslipped. Slides were analysed using a Zeiss LSM-510 confocal microscope or a Leica confocal microscope and analysed using Image (NIH).

Primary antibodies included rabbit anti-GFP (Molecular Probes; 1/1000); sheep anti-GFP (Biogenesis; 1/1000); rabbit anti-LacZ (Cappel; 1/1000); rabbit anti-APP (6900; Zymed; 1/1000); mouse anti-hAPP and A $\beta$ (4G8 and 6E10, Covance; $1 / 1000)$; rabbit anti-MOR28 $(1 / 3000)^{23}$, guinea pig anti-M71 $(1 / 1000)^{23}$, rabbit anti-activated caspase 3 (Cell Signaling; 1/500); rabbit anti-TROMA (Molecular Probes; 1:10) and mouse anti-tyrosine hydroxylase (Millipore; 1/500). Secondary antibodies were Alexa 488-conjugated donkey anti-rabbit Ig (Molecular Probes; 1/500), Alexa 488-conjugated donkey anti-sheep Ig (Molecular Probes; 1/500), Cy3-conjugated donkey anti-guinea pig Ig (Jackson Immunoresearch; 1/500), Cy3-conjugated rat anti-mouse Ig (Jackson Immunoresearch; 1/500).

In situ hybridization. Twenty-micrometre-thick, fresh frozen tissue sections were placed on Superfrost slides (Fisher Scientific). The sections were dried for $45 \mathrm{~min}$ at room temperature before fixing with $4 \%$ paraformaldehyde for $15 \mathrm{~min}$, and washed three times in $1 \times$ DEPC (diethylpyrocarbonate)-treated PBS containing $1 \mathrm{mM} \mathrm{MgCl}_{2}$. Slides were then immersed in a solution containing $270 \mathrm{ml}$ of
DEPC-treated water, $30 \mathrm{ml}$ of $1 \mathrm{M}$ triethanolamine and $750 \mu \mathrm{l}$ of $95 \%$ acetic anhydride for $10 \mathrm{~min}$, and subsequently washed three times in $1 \times \mathrm{DEPC}$-treated PBS containing $1 \mathrm{mM} \mathrm{MgCl}_{2}$. Slides were then blocked for $2 \mathrm{~h}$ with hybridization buffer: $0.1 \%$ Tween $20,50 \%$ formamide, $5 \times$ SSC, $5 \times$ Denhardts, 5 mM EDTA, $10 \mathrm{mM} \mathrm{NaH} 2 \mathrm{PO} 4$ at pH. 8.0, $50 \mathrm{mM}$ Tris $\mathrm{pH} 8.0,250 \mu \mathrm{g} \mathrm{ml}^{-1}$ salmon sperm DNA, $100 \mathrm{\mu g} \mathrm{ml}^{-1}$ tRNA and $100 \mu \mathrm{g} \mathrm{ml}^{-1}$ yeast RNA. Slides were dabbed dry and $A r c$ antisense RNA probes ${ }^{46}\left(100 \mu \mathrm{g} \mathrm{ml}^{-1}\right)$, preheated for $5 \mathrm{~min}$ at $80^{\circ} \mathrm{C}$ and cooled on ice for $2 \mathrm{~min}$, were applied to the slides and sealed in a humidified chamber at $65^{\circ} \mathrm{C}$ overnight. After $18 \mathrm{~h}$, the slides were washed at $65^{\circ} \mathrm{C}$ three times with $5 \times \mathrm{SSC}$ for $15 \mathrm{~min}$, and then three times with $0.2 \times \mathrm{SSC}$ for $20 \mathrm{~min}$. After blocking in $1 \times$ in situ hybridization blocking solution (Roche) for $1 \mathrm{~h}$, slides were dabbed dry and a sheep antibody-recognizing digoxetin (1/3000, Roche) was applied overnight. The next day, the RNA probe was detected using the HNPP fluorescent detection kit (Roche) or BCIP/NBT (Promega).

Whole mount. Whole mount analyses were performed as previously described ${ }^{47}$ Briefly, mice harbouring the P2-ires-GFP allele were anaesthesized as described above. The skull was dissected and then divided sagittally, and the dura was removed from the medial surface of each olfactory bulb. Each whole mount was placed in PBS with $2 \mathrm{mM} \mathrm{MgCl} 2$ and then imaged using a Leica confocal imaging system. Preparation and staining of olfactory bulbs expressing tau-LacZ was performed as previously described ${ }^{20}$.

AAV infection. AAV was introduced intranasally in one naris of a 2-month-old M71-ires-tauLacZ mice (Bri-A $\beta 40$ ) or control mice (Bri-A $\beta 42$ ) by diluting $2.5 \mu \mathrm{l}$ of AAV8 virus with $57.5 \mu \mathrm{l}$ of $2 \%$ methylcellulose in PBS ( $1 \%$ final concentration $\left.5 \times 10^{12} \mathrm{pfu}\right)$ as previously described ${ }^{48}$. Analysis by immunohistochemistry and whole mount preparation occurred 90 days after infection.

Behaviour. The TMT assay was derived from the curtain assay ${ }^{28}$. Briefly, the experiment was performed in the dark during the nocturnal phase of the day. The behavioural arena (Fig. 4a) was placed in a chemical hood. Mice (age range 3-5 months) were habituated to the arena three times for 10 min with blank filter papers. After $7 \mathrm{~min}$ of the third habituation, the filter papers were swapped with identical filter papers with $20 \mu \mathrm{l}$ of water or TMT, respectively. The remaining 3 min were video-recorded and scored in a blinded fashion. One-way analysis of variance and unpaired Student's $t$-tests were used to analyse the data.

The hidden food assay was derived from similar assays previously described 29,49 . The mice (age 3-9 months) were food-restricted for $24 \mathrm{~h}$ and then habituated in an $82 \times 63 \times 18 \mathrm{~cm}$ arena with $2 \mathrm{~cm}$ autoclaved mouse bedding 


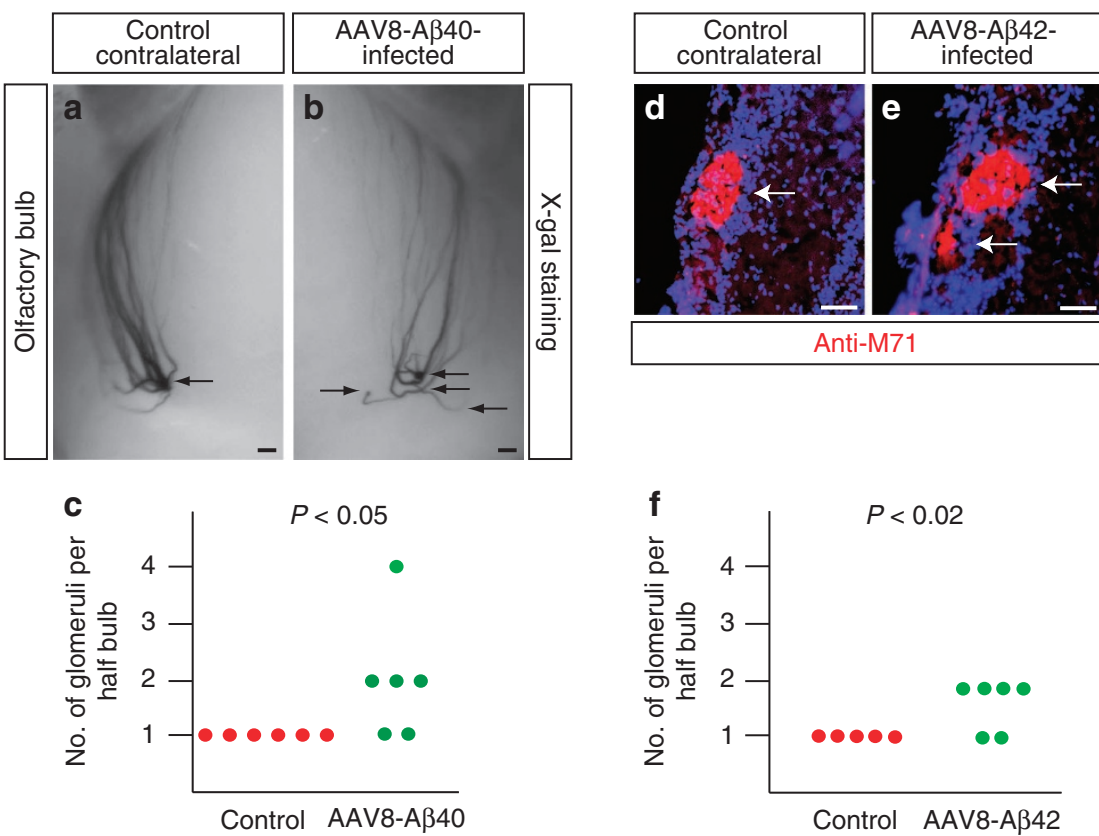

Figure 7 | A $\mathbf{\beta 4 0}$ and $\mathbf{A} \boldsymbol{\beta} 42$ expression in the olfactory epithelium alters $\mathbf{O S N}$ axon targeting. $(\mathbf{a}, \mathbf{b})$ Representative images of the olfactory bulbs from an M71-ires-tauLacZ mouse infected with AAV8-BriA 440 that were stained with X-gal (arrows indicate glomeruli receiving M71-expressing fibres). Scale bar $=200 \mu \mathrm{m}$. (c) Quantification of number of glomeruli receiving M71-expressing axons revealed a significant degree of mistargeting in the olfactory bulb ipsilateral to the AAV8-BriA 340 infection ( $P<0.05$; two-tailed Student's $t$-test; $n=6$ per genotype). (d,e) Representative images of the olfactory bulbs from a mouse infected with AAV8-BriA 342 immunostained with antibody that recognizes M71 (arrows identify glomeruli revealing M71-expressing fibres). Scale bar $=100 \mu \mathrm{m}$. (f) Quantification of number of glomeruli receiving M71-expressing axons revealed a significant degree of mistargeting in the olfactory bulb ipsilateral to the AAV8-BriA 342 infection ( $P<0.02$; two-tailed Student's $t$-test; $n=5$ (controls); $n=6$ (AAV8-BriA 442 ).

for $5 \mathrm{~min}$. Then they are returned to their home cage for $30 \mathrm{~min}$. Each animal was placed back in the arena with fresh autoclaved bedding covering $1 \mathrm{~g}$ of ground food pellet placed in one specific location. The trial was analysed in real time using a stopwatch until the food was ingested. The experimenters recording the latency to eat the food were blinded to the genotype. The results between the two experimenters were not significantly different. Each animal was tested once.

Statistical analysis. One-way analysis of variance and unpaired Student's $t$-tests were performed using SAS, Microsoft Excel or Apple Numbers, and results are presented as mean \pm s.e.m.

\section{References}

1. Palop, J. J. \& Mucke, L. Amyloid-beta-induced neuronal dysfunction in Alzheimer's disease: from synapses toward neural networks. Nat. Neurosci. 13, 812-818 (2010).

2. Sperling, R. A. et al. Amyloid deposition is associated with impaired default network function in older persons without dementia. Neuron 63, 178-188 (2009).

3. Hedden, T. et al. Disruption of functional connectivity in clinically normal older adults harboring amyloid burden. J. Neurosci. 29, 12686-12694 (2009).

4. Jack, C. R. Jr. et al. Serial PIB and MRI in normal, mild cognitive impairment and Alzheimer's disease: implications for sequence of pathological events in Alzheimer's disease. Brain 132, 1355-1365 (2009).

5. Sheng, M., Sabatini, B. L. \& Sudhof, T. C. Synapses and Alzheimer's disease. Cold Spring Harb Perspect Biol 4, pil: a005777. doi: 10.1101/cshperspect. a005777 (2012).

6. Ashe, K. H. \& Zahs, K. R. Probing the biology of Alzheimer's disease in mice. Neuron 66, 631-645 (2010).

7. Koffie, R. M. et al. Oligomeric amyloid beta associates with postsynaptic densities and correlates with excitatory synapse loss near senile plaques. Proc. Natl Acad. Sci. USA 106, 4012-4017 (2009).

8. Kuchibhotla, K. V. et al. Abeta plaques lead to aberrant regulation of calcium homeostasis in vivo resulting in structural and functional disruption of neuronal networks. Neuron 59, 214-225 (2008).

9. Mucke, L. et al. High-level neuronal expression of abeta 1-42 in wild-type human amyloid protein precursor transgenic mice: synaptotoxicity without plaque formation. J. Neurosci. 20, 4050-4058 (2000).

10. Li, S. et al. Soluble oligomers of amyloid beta protein facilitate hippocampal long-term depression by disrupting neuronal glutamate uptake. Neuron $\mathbf{6 2}$, 788-801 (2009).
11. Shankar, G. M. et al. Amyloid-beta protein dimers isolated directly from Alzheimer's brains impair synaptic plasticity and memory. Nat. Med. 14, 837-842 (2008).

12. Citron, M., Teplow, D. B. \& Selkoe, D. J. Generation of amyloid beta protein from its precursor is sequence specific. Neuron 14, 661-670 (1995).

13. Wei, W. et al. Amyloid beta from axons and dendrites reduces local spine number and plasticity. Nat. Neurosci. 13, 190-196 (2010).

14. Venkitaramani, D. V. et al. Beta-amyloid modulation of synaptic transmission and plasticity. J. Neurosci. 27, 11832-11837 (2007).

15. Hsieh, H. et al. AMPAR removal underlies Abeta-induced synaptic depression and dendritic spine loss. Neuron 52, 831-843 (2006).

16. Albers, M. W., Tabert, M. H. \& Devanand, D. P. Olfactory dysfunction as a predictor of neurodegenerative disease. Curr. Neurol. Neurosci. Rep. 6, 379-386 (2006).

17. Vassar, R. et al. Topographic organization of sensory projections to the olfactory bulb. Cell 79, 981-991 (1994).

18. Malnic, B., Hirono, J., Sato, T. \& Buck, L. B. Combinatorial receptor codes for odors. Cell 96, 713-723 (1999).

19. Feinstein, P. \& Mombaerts, P. A contextual model for axonal sorting into glomeruli in the mouse olfactory system. Cell 117, 817-831 (2004).

20. Wang, F., Nemes, A., Mendelsohn, M. \& Axel, R. Odorant receptors govern the formation of a precise topographic map. Cell 93, 47-60 (1998).

21. Mullan, M. et al. A pathogenic mutation for probable Alzheimer's disease in the APP gene at the N-terminus of beta-amyloid. Nat. Genet. 1, 345-347 (1992).

22. Hsiao, K. et al. Correlative memory deficits, Abeta elevation, and amyloid plaques in transgenic mice. Science 274, 99-102 (1996).

23. Barnea, G. et al. Odorant receptors on axon termini in the brain. Science 304, 1468 (2004).

24. Kistner, A. et al. Doxycycline-mediated quantitative and tissue-specific control of gene expression in transgenic mice. Proc. Natl Acad. Sci. USA 93, 10933-10938 (1996).

25. Yu, C. R. et al. Spontaneous neural activity is required for the establishment and maintenance of the olfactory sensory map. Neuron 42, 553-566 (2004).

26. Feinstein, P., Bozza, T., Rodriguez, I., Vassalli, A. \& Mombaerts, P. Axon guidance of mouse olfactory sensory neurons by odorant receptors and the beta2 adrenergic receptor. Cell 117, 833-846 (2004).

27. Cheng, N., Cai, H. \& Belluscio, L. In vivo olfactory model of APP-induced neurodegeneration reveals a reversible cell-autonomous function. J. Neurosci. 31, 13699-13704 (2011). 
28. Kobayakawa, K. et al. Innate versus learned odour processing in the mouse olfactory bulb. Nature 450, 503-508 (2007).

29. Fleming, S. M. et al. Olfactory deficits in mice overexpressing human wildtype alpha-synuclein. Eur. J. Neurosci. 28, 247-256 (2008).

30. Baker, H. Unilateral, neonatal olfactory deprivation alters tyrosine hydroxylase expression but not aromatic amino acid decarboxylase or GABA immunoreactivity. Neuroscience 36, 761-771 (1990).

31. Lawlor, P. A. et al. Novel rat Alzheimer's disease models based on AAVmediated gene transfer to selectively increase hippocampal Abeta levels. Mol. Neurodegener. 2, 11 (2007).

32. Gottfried, J. A. Central mechanisms of odour object perception. Nat. Rev. Neurosci. 11, 628-641 (2010)

33. Wilson, D. A. \& Sullivan, R. M. Cortical processing of odor objects. Neuron 72, 506-519 (2011).

34. Wesson, D. W., Levy, E., Nixon, R. A. \& Wilson, D. A. Olfactory dysfunction correlates with amyloid-beta burden in an Alzheimer's disease mouse model. J. Neurosci. 30, 505-514 (2010).

35. Wesson, D. W. et al. Sensory network dysfunction, behavioral impairments, and their reversibility in an Alzheimer's beta-amyloidosis mouse model. J. Neurosci. 31, 15962-15971 (2011).

36. Graziadei, P. P. \& Graziadei, G. A. Neurogenesis and neuron regeneration in the olfactory system of mammals. I. Morphological aspects of differentiation and structural organization of the olfactory sensory neurons. J. Neurocytol. 8, 1-18 (1979).

37. Gogos, J. A., Osborne, J., Nemes, A., Mendelsohn, M. \& Axel, R. Genetic ablation and restoration of the olfactory topographic map. Cell 103, 609-620 (2000).

38. Kamenetz, F. et al. APP processing and synaptic function. Neuron 37, 925-937 (2003).

39. Qiang, L. et al. Directed conversion of Alzheimer's disease patient skin fibroblasts into functional neurons. Cell 146, 359-371 (2011).

40. Cao, L., Rickenbacher, G. T., Rodriguez, S., Moulia, T. W. \& Albers, M. W. The precision of axon targeting of mouse olfactory sensory neurons requires the BACE1 protease. Sci. Rep. 2, 1-8 (2012).

41. O'Connor, T. et al. Phosphorylation of the translation initiation factor eIF2alpha increases BACE1 levels and promotes amyloidogenesis. Neuron 60, 988-1009 (2008).

42. Reitz, C., Brayne, C. \& Mayeux, R. Epidemiology of Alzheimer disease. Nat. Rev. Neurol. 7, 137-152 (2011).

43. Mombaerts, P. et al. Visualizing an olfactory sensory map. Cell 87, 675-686 (1996).

44. Shah, N. M. et al. Visualizing sexual dimorphism in the brain. Neuron 43, 313-319 (2004).

45. Cao, L. et al. Genetic modulation of BDNF signaling affects the outcome of axonal competition in vivo. Curr. Biol. 17, 911-921 (2007).
46. William, C. M. et al. Synaptic plasticity defect following visual deprivation in Alzheimer's disease transgenic mice. J. Neurosci. 32, 8004-8011 (2012).

47. Shykind, B. M. et al. Gene switching and the stability of odorant receptor gene choice. Cell 117, 801-815 (2004).

48. Gau, P., Rodriguez, S., De Leonardis, C., Chen, P. \& Lin, D. M. Air-assisted intranasal instillation enhances adenoviral delivery to the olfactory epithelium and respiratory tract. Gene Ther 18, 432-436 (2011).

49. Crawley, J. N. What's Wrong With My Mouse? (Wiley-Liss: New York, 2000).

\section{Acknowledgements}

We thank R. Axel, S.D. Liberles and A.D. Albers for insightful comments; A. Nemes, M. Mendelssohn and J. Kirkland for generating the CORMAP mouse lines; L. Wu for generating the CORMAC mouse lines; C. M. William for the Arc in situ probe; H. Brown, N. Bevins, H. Wei, N. Propp, M. Glinka, M. Hood and Z. Doctor for excellent technical assistance; M. Arimon for performing the ELISA; and G. Sun for statistical analyses. This work was supported by the AFAR-Ellison Foundation (awarded to L.C.), the NIH (K08 DC04807 and DP2 OD006662, awarded to M.W.A.; P30AG036449, awarded to B.T.H.), and the Rappaport Foundation (awarded to M.W.A.).

\section{Author contributions}

L.C., S.R. and M.W.A. designed the research; L.C., B.R.S., S.R., E.G.B., T.W.M., G.T.R., A.C.G., Y.L., S.R.E. and M.W.A. performed experiments; T.E.G., B.T.H. and G.B. contributed new reagents and analytic tools; L.C., B.R.S., S.R., E.G.B., T.W.M., G.T.R. and M.W.A. analysed data; M.W.A. wrote the initial draft; all authors reviewed and revised the paper.

\section{Additional information}

Supplementary Information accompanies this paper at http://www.nature.com/ naturecommunications

Competing financial interests: T.E.G. has received support from Myriad Genetics and Lunkbeck, Inc. T.E.G. has consulted for Elan, Lundbeck Inc., Sonexa Therapeutics and Kareus Therapeutics. B.T.H. has consulted for EMD Serrano, Janssen, Takeda, BMS, Neurophage, Pfizer, Quanterix, foldrx, Elan and Link.

Reprints and permission information is available online at http://npg.nature.com/ reprintsandpermissions/

How to cite this article: Cao, L. et al. A $\beta$ alters the connectivity of olfactory neurons in the absence of amyloid plaques in vivo. Nat. Commun. 3:1009 doi: 10.1038/ncomms2013 (2012). 